\title{
APLIKASI DATA SATWA YANG DI LINDUNGI DI INDONESIA BERBASIS GIS DAN CSS BOOTSTRAP ( Studi Kasus: Kebun Binatang Surabaya )
}

\author{
Sudarmaji $^{1}$, Tjahjaning Tingastuti Surjosuseno ${ }^{2}$ \\ DISPENDIK \& Sekolah Tinggi Teknologi Cahaya Surya Kediri \\ ${ }^{1}$ sudarmajikdr@gmail.com \& ${ }^{2}$ mariasurjosuseno@gmail.com
}

\begin{abstract}
ABSTRAK
Indonesia adalah negara tropis yang kaya akan berbagai sumber daya alam salah satunya adalah satwa. Satwa di Indonesia tersebar diseluruh kepulauan dari Sabang sampai Merauke, dan memiliki keanekaragaman yang berbeda-beda. Masyarakat Indonesia hendaknya mengetahui informasi tentang satwa langka, maka dari itu di perlukan suatu aplikasi untuk mendata satwa langka yang ada di Indonesia, agar masyarakat bisa mengakses dan mengetahui tentang informasi satwa langka. Media website dipilih agar lebih menarik, interaktif dan dapat memudahkan masyarakat dalam mengunduh informasi jenis-jenis satwa yang dilindungi melalui internet dari berbagai lokasi.Aplikasi data satwa berbasis Geographic Information System ( GIS ) dan CSS Bootstrap menggunakan PHP module dan database MySQL menghasilkan informasi berupa data satwa yang ada di Indonesia berdasarkan Lampiran Peraturan Menteri Lingkungan Hidup Dan Kehutanan Republik Indonesia Nomor P.20/Menlhk/Setjen/Kum.1/6/2018 untuk memberikan informasi dan pengetahuan seputar satwa yang ada di indonesia.
\end{abstract}

Kata Kunci: Satwa langka, Aplikasi php, Bootstrap, Google Maps, MySQL. 


\begin{abstract}
Indonesia is a tropical country that is rich in various natural resources, one of which is animals. Animals in Indonesia are scattered throughout the islands from Sabang to Merauke, and have varying diversity. Indonesian people should know information about endangered species, and therefore need an application to record endangered species in Indonesia, so that people can access and find out about information on endangered species. Media websites are chosen to be more attractive, interactive and can make it easier for people to download information on protected species via the internet from various locations. Animal data applications based on Geographic Information System (GIS) and CSS Bootstrap use PHP modules and MySQL databases to produce data in the form of data animals in Indonesia based on the Appendix of the Republic of Indonesia Minister of Environment and Forestry Regulation Number P.20 / Menlhk / Setjen / Kum.1 / 6/2018 to provide information and knowledge about animals in Indonesia.
\end{abstract}

Key words: Endangered animals, PHP applications, Bootstrap, Google Maps, MySQL. 
ISSN: 2302-2426

ISSN on Line: $2580-2399$

\section{PENDAHULUAN}

Satwa langka adalah hewan yang hampir terancam punah dari keberadaannya akibat dari keserakahan manusia yang melakukan penebangan hutan secara liar yang merupakan habitat dan ekosistem dari hewan tersebut. Disamping itu yang menyebabkan kepunahan mereka adalah pembakaran hutan baik yang disebabkan oleh pemanasan global maupun adanya kesengajaan dari manusia itu sendiri dengan tujuan untuk memperluas areal pertanian ataupun memperluas wilayah pemukiman.

Banyaknya hiasan-hiasan yang menggunakan tulang belulang dari hewan dengan harga yang lebih mahal, menjadikan perburuan dan perdagangan hewan menjadi semakin meningkat tanpa mengindahkan punahnya keberadaan hewan tersebut. Pemerintah telah menerbitkan peraturan pelaksanaan Undang-undang Mengenai satwa langka tersebut. Pada Lampiran Peraturan Menteri Lingkungan Hidup Dan Kehutanan Republik Indonesia Nomor P.20/MENLHK/SETJEN/KUM.1/6/2018 telah ditetapkan jenis-jenis satwa yang dilindungi. Jenis-jenis satwa yang ditetapkan sebagai jenis satwa yang dilindungi karena satwa tersebut memiliki nilai ekonomis yang tinggi dan jumlah persebarannya pada saat ini makin terancam kepunahan sehingga satwa tersebut akan menjadi langka.Penduduk asli Indonesia yang baik, wajib untuk melindungi keberadaan hewan-hewan langka tersebut, akan tetapi kurangnya informasi pendataan dan keberadaan tentang hewan-hewan langka menjadi kendala untuk mengoptimalkan pelestarian hewan-hewan langka.

Dari ilustrasi diatas penulis mencoba membuat suatu sarana aplikasi berbasis web dengan judul “APLIKASI DATA SATWA YANG DI LINDUNGI DI INDONESIA BERBASIS GIS DAN CSS BOOTSTRAP" dengan aplikasi yang bertujuan untuk memberikan informasi-informasi mengenai satwa langka yang di lindungi dan khas daerah masing-masing yang ada di Indonesia. Media website dipilih agar lebih menarik, interaktif dan dapat memudahkan masyarakat dalam mengunduh informasi jenis-jenis satwa yang dilindungi melalui internet dari berbagai lokasi. 


\section{LANDASAN TEORI}

Teori yang digunakan dalam pembuatan aplikasi data satwa langka ini, teori yang digunakan adalah bahasa pemograman PHP (Hypertext Preprocessor), Basis Data MySQL, Template CSS Bootstrap, DFD ( Data Flow Diagram), dan ERD (Entity Relationship Diagram).

Dalam pembuatan aplikasi data satwa, landasan teori ini digunakan untuk menandai lokasi penyebaran satwa. Menurut Prahasta (2009;1O) Sistem Geographic Information System disingkat GIS adalah sistem informasi khusus yang mengelola data yang memiliki informasi spasial ( letak geografis ). Google API bisa di katakan bagian dari Framework Google. Google menyediakan berbagai API (Application Programming Interface) yang sangat berguna bagi pengembang web maupun aplikasi desktop untuk memanfaatkan berbagai fitur yang disediakan oleh Google seperti misalnya: AdSense, Search Engine, Translation maupun YouTube.

API secara sederhana bisa diartikan sebagai kode program yang merupakan antarmuka atau penghubung antara aplikasi atau web yang kita buat dengan fungsifungsi yang dikerjakan. Misalnya kita bisa menambahkan fitur Google Map pada website kita.

Google API dapat dipelajari Langsung melalui Google Code. Ada banyak API yang disediakan oleh Google, beberapa diantaranya adalah sebagai berikut:

1.Language API : untuk memanfaatkan fitur translation yang dimiliki Google.

2. Earth API : memanfatkan fitur yang ada pada Google Earth Javascript API

3. Maps API : memanfaatkan fitur yang ada pada Google Maps

4. Search API : memanfaatkan fitur pencarian pada Google Search

5. Visualization API : membuat grafik maupun chart Google API

Salah satu cara mudah mempelajari Google API adalah dengan memanfaatkan Google AJAX APIs Playground. AJAX APIs playground adalah sebuah situs yang disediakan oleh Google bagi kita untuk mencoba secara langsung sejumlah Google API yang berbasis AJAX (Asynchronous Javascript and XML).

Dalam pembuatan aplikasi data satwa, landasan teori ini digunakan untuk desain template website aplikasi data satwa. Menurut Alantas (2013) Bootstrap adalah platform baru yang dikembangkan tim twitter. Platform ini hanya menggunakan sedikit coding CSS dan JavaScript namun tetap bisa membuat website yang powerfull mengikuti 
perkembangan browser. Website yang menggunakan bootstrap akan menjadikan website yang fleksibel, nyaman dan tentu saja cepat.

Dalam pembuatan aplikasi data satwa, landasan teori ini digunakan untuk desain database aplikasi data satwa. Menurut Abdul Kadir ( 2013) My SQL adaalah sebuah server database open source yang terkenal yang digunakan berbagai aplikasi terutama untuk server atau membuat website. Mysql berfungsi sebagai SQL (Structured Query Language) yang dimiliki sendiri dan sudah diperluas oleh Mysql umumnya digunakan bersamaan dengan PHP untuk membuat aplikasi server yang dinamis dan powerfull.

Kehandalan suatu sistem basis data dapat diketahui dari cara kerja pengoptimasinya dalam melakukan proses perintah-perintah SQL yang dibuat oleh pengguna maupun program-program aplikasi yang memanfaatkannya. Sebagai peladen basis data, MySQL mendukung operasi basis data transaksional maupun operasi basis data non-transaksional. Pada modul operasi non-transaksional, MySQL dapat dikatakan unggul dalam hal unjuk kerja dibandingkan perangkat lunak server basis data kompetitor lainnya. Namun demikian pada modul non-transaksional tidak ada jaminan atas reliabilitas terhadap data yang tersimpan, karenanya modul non-transaksional hanya cocok untuk jenis aplikasi yang tidak membutuhkan reliabilitas data seperti aplikasi blogging berbasis web (wordpress), CMS, dan sejenisnya. Untuk kebutuhan sistem yang ditujukan untuk bisnis sangat disarankan untuk menggunakan modul basis data transaksional, hanya saja sebagai konsekuensinya unjuk kerja MySQL pada modul transaksional tidak secepat unjuk kerja pada modul non-transaksional.

\section{METODE PENELITIAN}

\subsection{Analisa Kebutuhan}

Analisa kebutuhan sistem bertujuan untuk mengidentifikasi kebutuhan hardware, software dan bahan yang akan digunakan dalam mendukung penelitian serta fitur yang akan dibuat untuk aplikasi. Analisis ini diperlukan sebagai dasar bagi tahapan perancangan sistem dan untuk mengamati bagaimana sistem akan berjalan. Pada umumnya pencarian informasi tentang satwa dilakukan dengan mencari data informasi satwa dengan datang langsung ke tempat konservasi atau ke kebun binatang misalnya ke kebun binatang Surabaya. Tetapi ada juga yang mencari inforamsi dengan mencari atau browsing melalui internet, dengan mencari informasi satwa dari berbagai sumber 
dan situs web yang bermacam-macam sehingga kadang kala ada informasi yang tidak sama mengenai informasi satwa dan kebenaran data satwa tersebut.

Setelah penggunaan aplikasi data satwa ini, maka masyarakat yang membutuhkan informasi mengenai satwa tidak perlu mencari dari berbagai sumber yang kadang informasinya berbeda, karena di aplikasi ini telah merangkum berbagai informasi satwa yang ada di indonesia dan juga mencakup satwa yang dilindungi sesuai undang-undang, data-data satwa ini diambil dari lembaga konservasi atau kebun binatang sebagai salah satu contohnya adalah dari kebun binatang Surabaya, dan juga di dukung oleh pemilik yaitu lembaga konsevasi atau kebun bianatang yang memberikan data satwanya di aplikasi ini, jadi informasi mengenai satwa bisa lebih valid dan lengkap. Pengguna dalam aplikasi satwa ini ada 3 pengguna yaitu sebagai berikut :

1. Admin

2. Pemilik/pemilik

3. Pengunjung

3.1.1 Pengumpulan Data Penelitian Pada penelitian ini dibutuhkan pengumpulan data-data tertentu yang diperoleh dari beberapa tahapan, di antaranya yaitu :

a. Studi Literatur

Studi Literatur ini dilakukan dengan cara mengumpulkan, membaca dan mempelajari sejumlah referensi baik dari buku-buku dan web di internet yang berhubungan GIS, CSS Bootstrap, PHP, MySql dan Satwa langka .

b. Pengamatan (Observasi)

Pengumpulan data juaga dilakukan dengan Proses observasi dilakukan pengamatan tentang satwa langka di Kebun Binatang Surabaya untuk mendapatkan data jenis satwa langka yang ada di tempat konservasi satwa tersebut dan tempat satwa langka tersebut.

c. Dokumen

Pengumpulan data melalui dokumen tertulis maupun elektronik dari lembaga / institusi tentang jenis satwa serta tempat satwa langka. Dokumen itu diperlukan untuk mendukung kelengkapan pengumpulan data satwa langka. 


\subsection{Perancangan Arsitektur Sistem}

Rancangan sistem sangat diperlukan agar arsitektur sistem dapat memenuhi fungsionalitas yang diinginkan oleh pengguna. Fungsi aplikasi yang dimiliki oleh Admin adalah :

1. Admin dapat melakukan login.

2. Admin dapat mengelola semua menu yang ada di aplikasi data satwa langka ini seperti menambah atau mengedit data satwa dan menghapusnya.

3. Admin juga dapat menambah user pada pemilik yang hak akses pemilik hanya bisa menambah data satwa saja.

4. Share ke media sosial data satwa langka

Fungsi aplikasi yang dimiliki oleh pemilik adalah :

1. Pemilik dapat melakukan login.

2. Pemilik dapat menambah semua menu yang ada di aplikasi data satwa langka. Pemilik tidak boleh menghapus data satwa tetapi hanya memiliki menu sebatas tambah dan edit satwa.

3. Menambahkan data satwa langka yang ada di tempat konservasi yang di kelola, yang mungkin belum ada di aplikasi

4. Mempublikasi/share data satwa ke media sosial (Facebook, Whatsapp, Twitter, Line, Pinterest dan lainnya).

5. Pemilik merupakan Lembaga Konservasi misal: Suaka Margasatwa.

Fungsi aplikasi yang dimiliki pengunjung adalah :

1. Melihat data satwa langka di Indonesia

2. Mencari data satwa berdasar : Pulau, Provinsi, Kecamatan atau dengan kata kunci.

3. Mempublikasi/share data satwa ke media sosial (Facebook, Whatsapp, Twitter, Line, Pinterest dan lainnya).

Arsitektur aplikasi data satwa yang di lindungi di Indonesia akan ditunjukkan pada Gambar 2.2. Aplikasi ini didukung dengan perangkat $P C$ dan MySQL sebagai database dari Aplikasi Data Satwa Langka. 


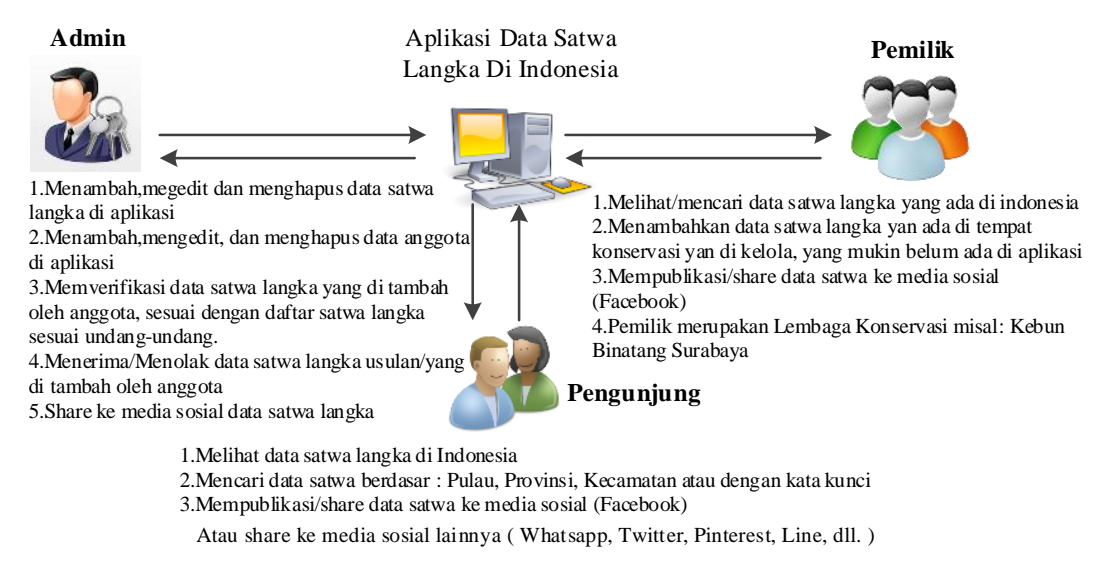

Gambar 3.2 Arsitektur Aplikasi Data Satwa

Arsitektur aplikasi pada Gambar 2.2 menjelaskan bahwa penggunaan aplikasi memiliki hubungan antara admin, pengunjung dan pemilik dengan aplikasi data satwa langka. Admin megelola aplikasi dengan menambah,mengedit dan mengahapus data dari satwa langka, admin juga bisa menambah, mengedit dan mengahapus data pemilik yang ada di aplikasi ini. Sebagai pemilik di aplikasi data satwa ini bisa mencari dan mempublikasi data-data satwa langka melalui media sosial (Facebook, Whatsapp, Twitter, Line, Pinterest dan lainnya), dan pemilik bisa menambahkan data satwa langka yang ada di tempat konsevasi yang di kelolanya dan mungkin saja data satwa tersebut belum ada di aplikasi data satwa ini. Untuk pengunjung bisa melihat informasi mengenai satwa langka dan mempublikasikanya/share ke media sosial, kemudian bisa juga mencari satwa langka berdasarkan Pulau, Provinsi, atau dengan mengunakan pencarian per Kategori satwa dan kata kunci sehingga di pencarian data satwa lebih maksimal dan membantu dalam pencarian data satwa.

\subsubsection{Flowcart Diagram}

Flowcart Diagram atau aliran informasi mewakili cara dimana data dan control berubah pada saat bergerak melalui sebuah system . Aliran informasi-informasi yang ada adalah sebagai berikut : 
ISSN: 2302-2426

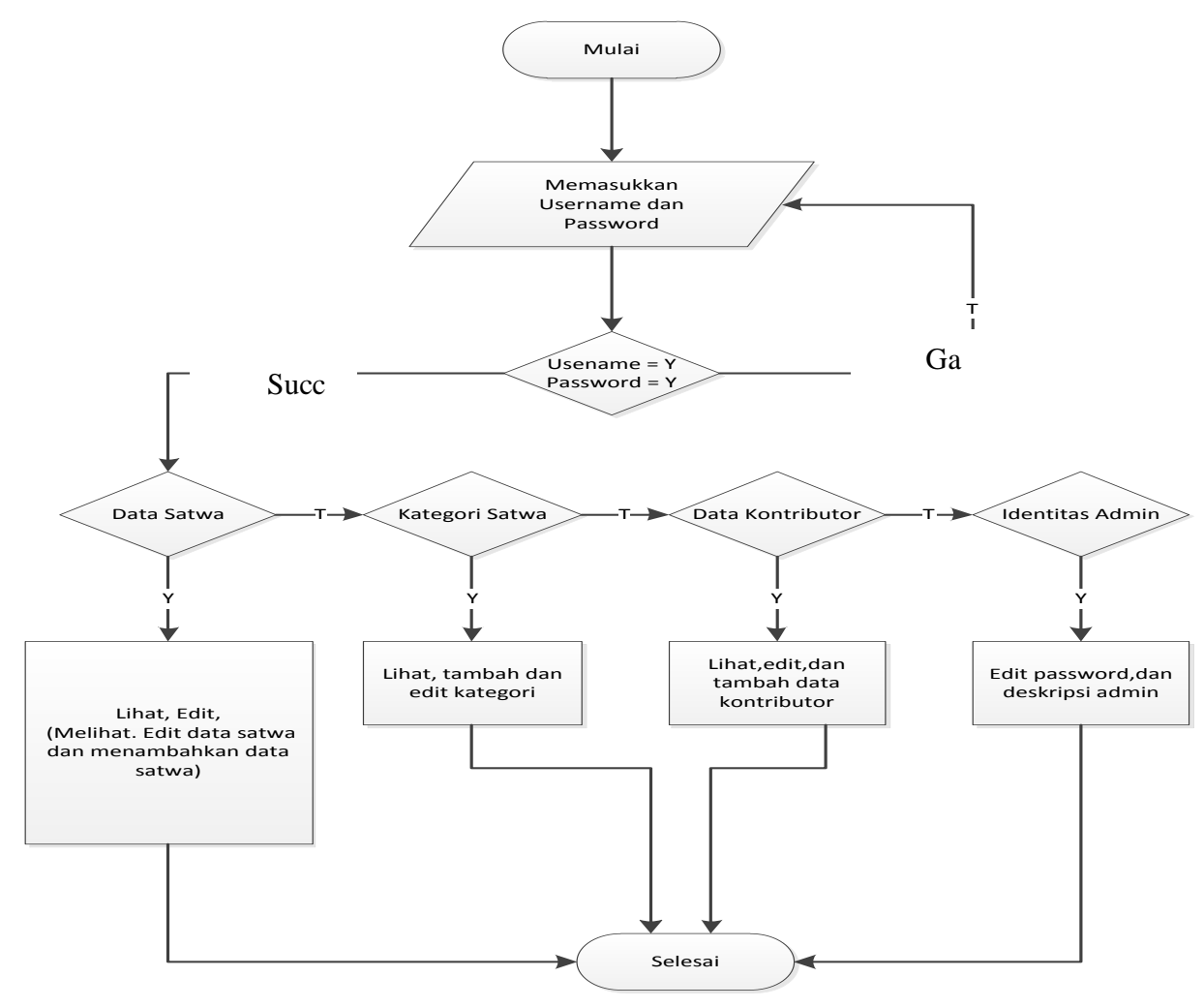

Gambar 3.2.1. Flowchart diagram untuk admin

Berdasarkan flowchart diagram untuk admin di atas maka dapat di jelaskan alurnya sebagai berikut :

1. Pertama dilakukan oleh admin adalah melakukan login jika login gagal maka admin harus mengulangin login dan jika login sudah benar maka admin dapat masuk pada halaman menu admin.

2. Pada data data satwa, admin dapat melakukan lihat, edit dan menghapus.

3. Pada data kategori, admin dapat melakukan lihat ,edit dan hapus.

4. Admin dapat melakukan penggantian password. 


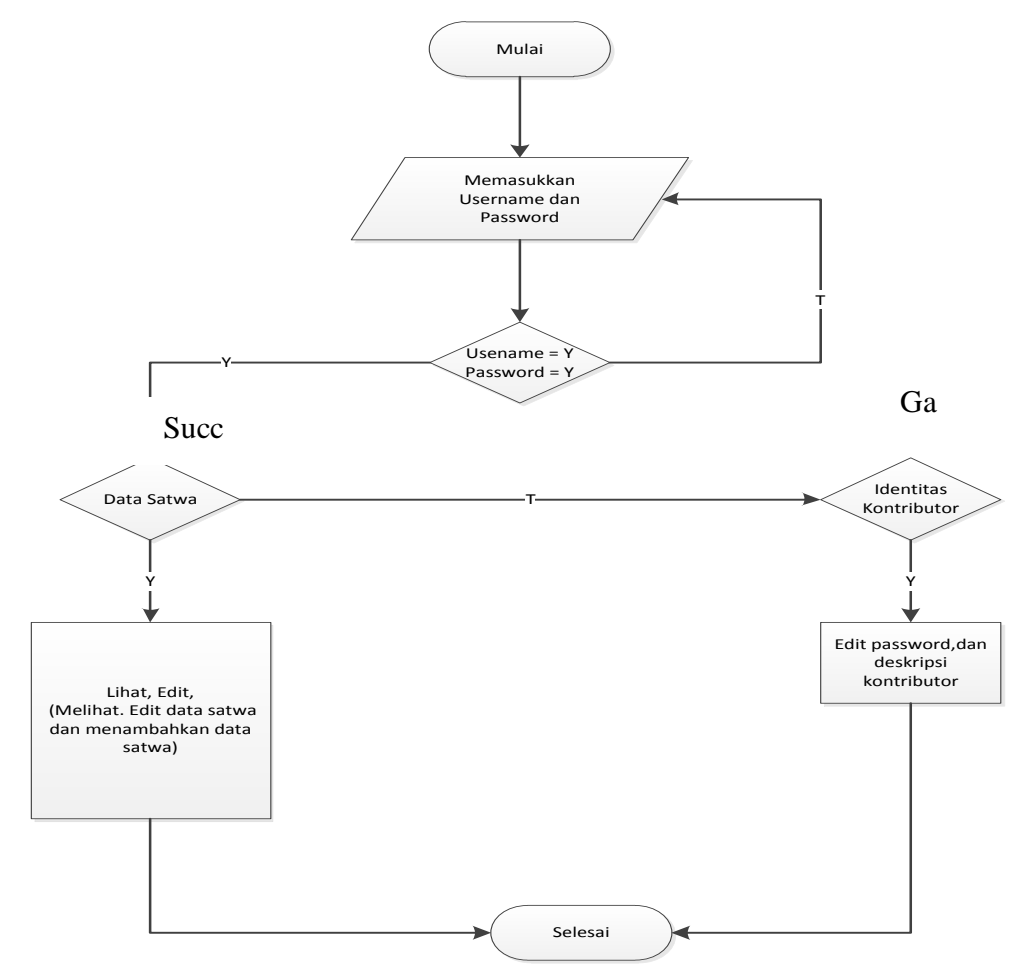

Gambar 3.2.2. Flowcart diagram untuk pemilik

Berdasarkan flochart diagram untuk pemilik di atas maka dapat di jelaskan alurnya sebagai berikut :

1. Pertama dilakukan oleh pemilik adalah melakukan login jika login gagal maka admin harus mengulangin login dan jika login sudah benar maka admin dapat masuk pada halaman menu pemilik.

2. Pada data data satwa, pemilik dapat melakukan lihat, edit dan menghapus.

3. Pemilik dapat melakukan penggantian password. 


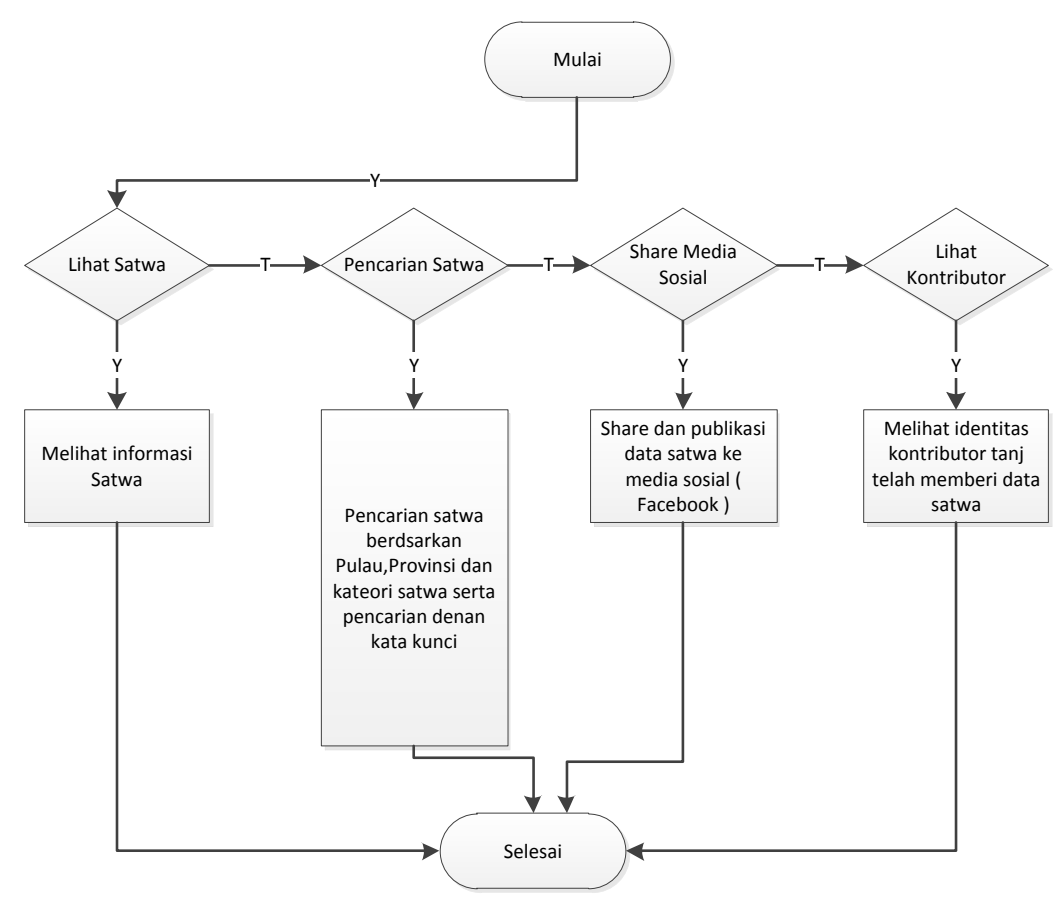

Gambar 3.2.3. Flowcart diagram untuk pengunjung

Berdasarkan flowchart diagram untuk pengunjung di atas maka dapat di jelaskan alurnya sebagai berikut :

1. Pertama dilakukan oleh pengunjung adalah dapat melihat data satwa pada aplikasi.

2. Pengunjung dapat melakukan pencarian satwa berdasarkan kategori satwa, pulau, provinsi dan dengan pencarian kata kunci.

3. Pengunjung dapat mempublikasikan informasi satwa ke media sosial.

\subsection{Perancangan Data Flow Diagram (DFD)}

Pada bagian ini akan dijelaskan mengenai aliran data yang terjadi di dalam sistem aplikasi, dengan menggunakan gambaran dalam bentuk Data Flow Diagram (DFD) atau diagram alir data. Perancangan DFD pada penelitian ini mengacu pada buku yang ditulis oleh Pressman, R. S. (2010). Tingkat atau level tertinggi DFD adalah level 0 yang menggambarkan proses secara umum. Semakin tinggi level (level 1, level 2, ...dst), maka penjelasan sistem akan semakin detail.

\subsubsection{Diagram Konteks}

Diagram konteks merupakan level tertinggi dari DFD yang menggambarkan secara luas tentang seluruh input - output dalam sistem aplikasi yang dibangun seperti yang digambarkan pada Gambar 3.5. 


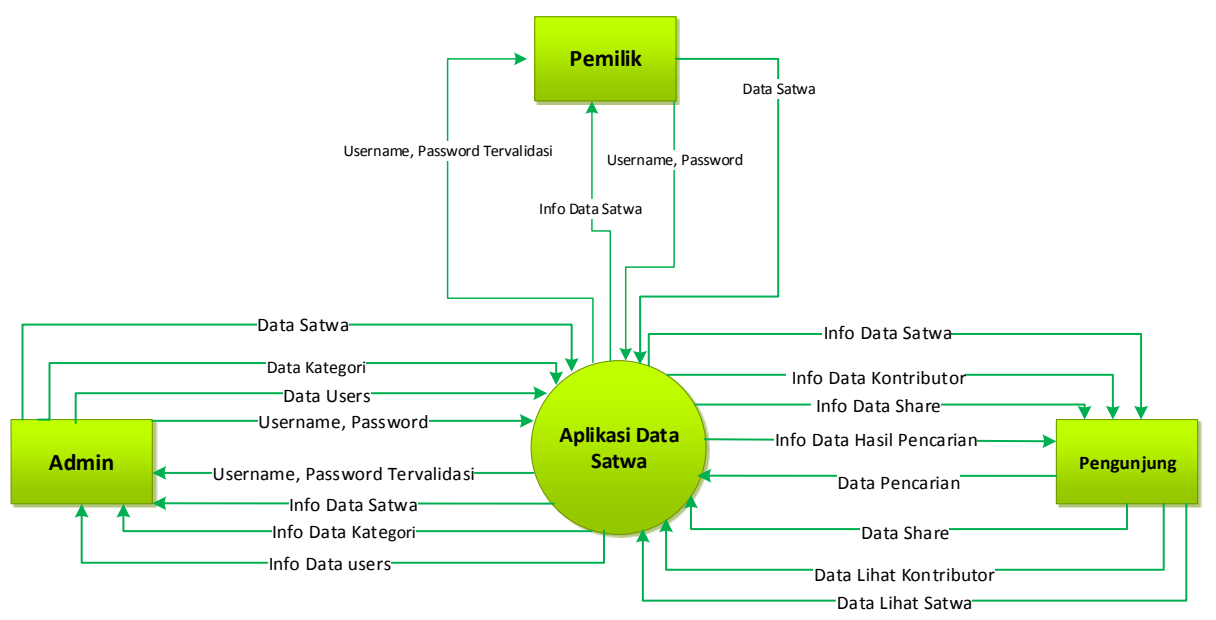

Gambar 3.3.1. Diagram konteks aplikasi data satwa

Penjelasan berdasarkan Gambar 2.3.1 diatas yaitu Dari proses diagram konteks diatas menjelaskan proses admin, pemilik dan pengunjung di dalam Aplikasi data satwa secara umum. Untuk admin mempunyai user dan password untuk login selain itu tugas admin disini untuk mengolah data satwa, data kategori, data lokasi, dan data yang dibutuhkan lainnya, sedangkan untuk pemilik hampir sama hanya saja hak aksesnya sebatas menambhakan data satwa saja. Dan pengunjung hanya bisa melihat dan mencari data satwa.

\section{Diagram level 0}

Diagram level 1 menggambarkan lebih detail proses - proses yang terdapat dalam sistem aplikasi seperti yang ditunjukkan Gambar 2.3.2 dibawah

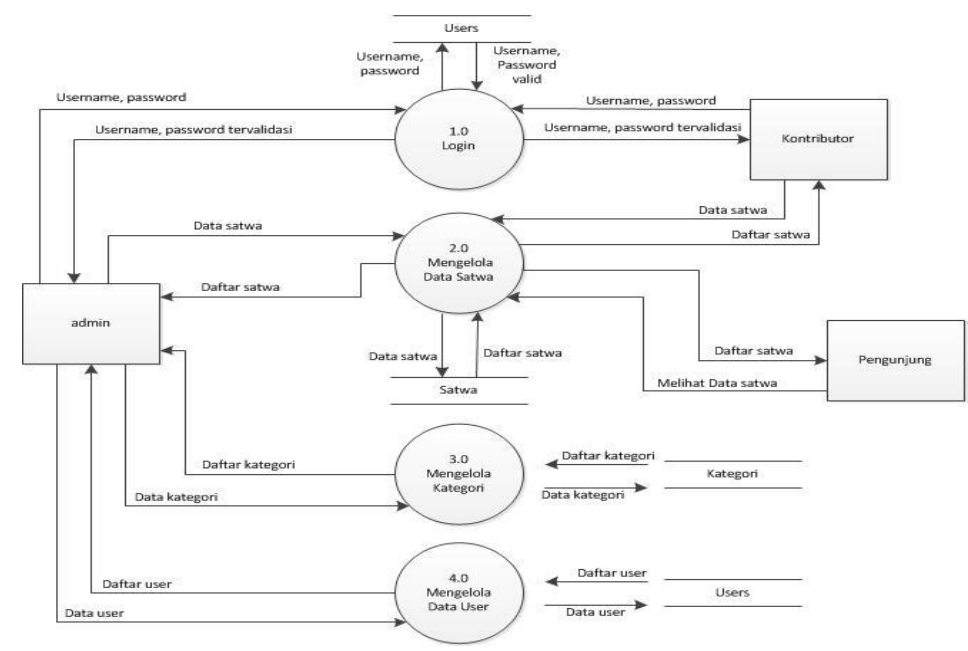

Gambar 3.3.2. DFD Level 0 aplikasi data satwa

Diagram level 1 Mengelola data satwa 
Diagram level 1 mengelola data satwa menggambarkan lebih detail proses - proses yang terdapat dalam mengelola data satwa pada sistem aplikasi data satwa ini, seperti yang ditunjukkan Gambar 2.3.3.

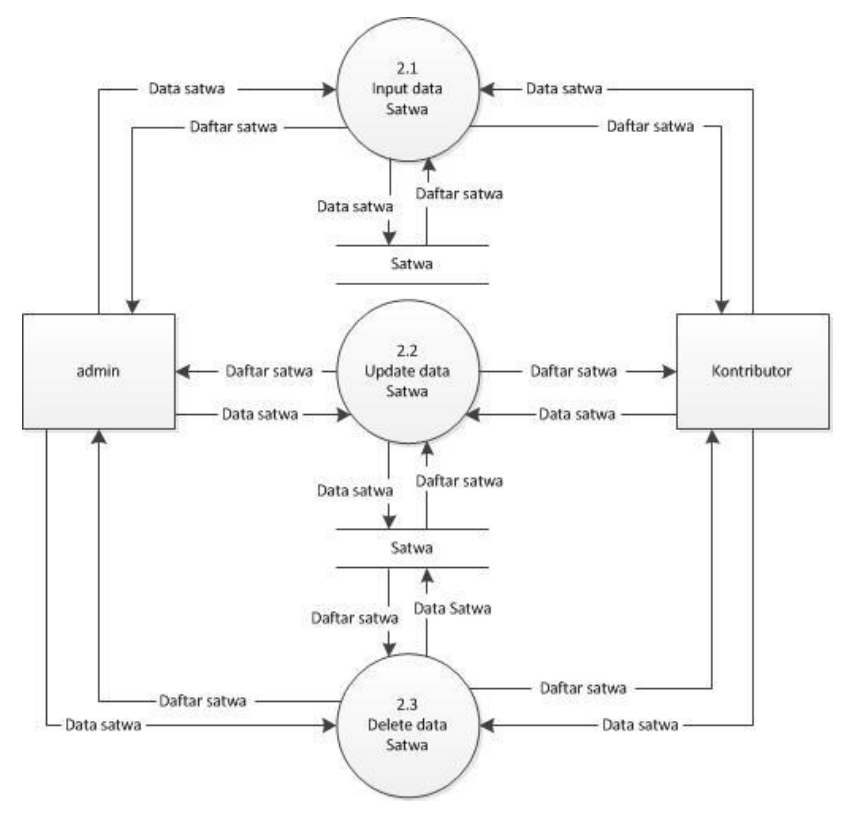

Gambar 3.3.3. DFD Level 1 mengelola data satwa

\section{Diagram Level 1 Mengelola Kategori}

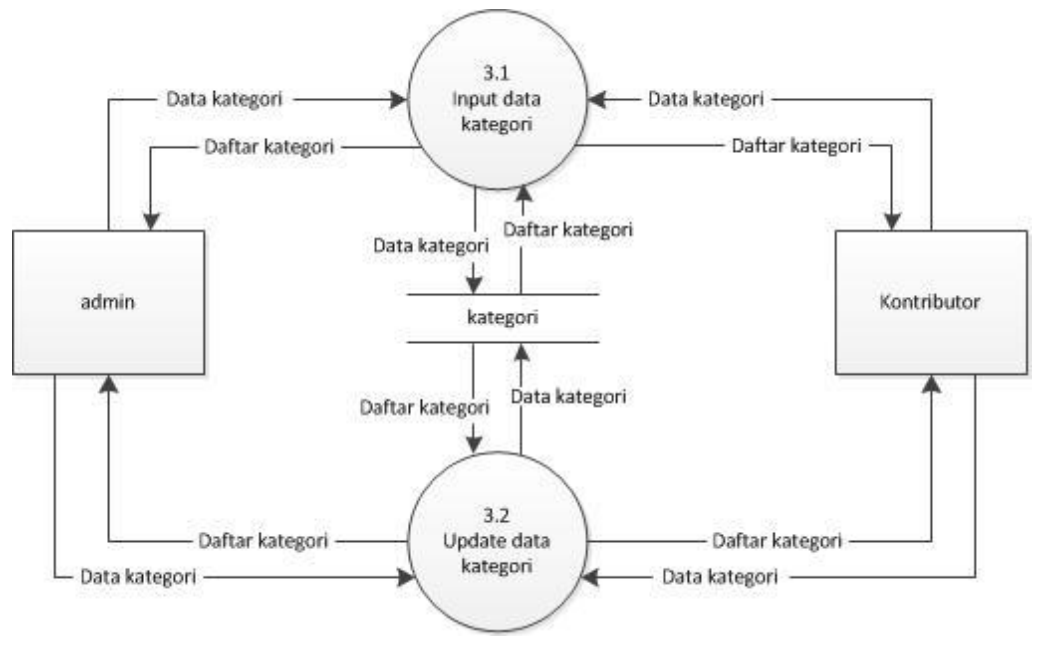

Gambar 3.3.4. DFD Level 1 mengelola kategori 


\section{Diagram Level 1 Mengelola Users}

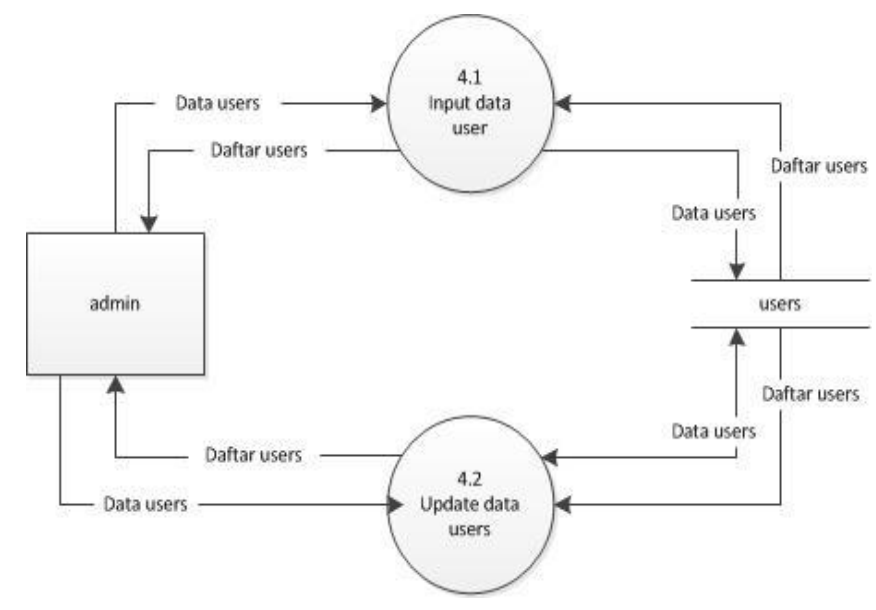

Gambar 3.3.5. DFD Level 1 mengelola data users

\subsection{Entity Relationship Diagram (ERD)}

ERD menunjukkan menunjukan informasi yang dibuat, disimpan dan digunakan dalam sebuah sistem aplikasi. Selain itu ERD juga digunakan untuk menunjukan aturanaturan alur dari database yang ada di implementasikan ke aplikasi tersebut. Berikut ini adalah ERD dari aplikasi data satwa.

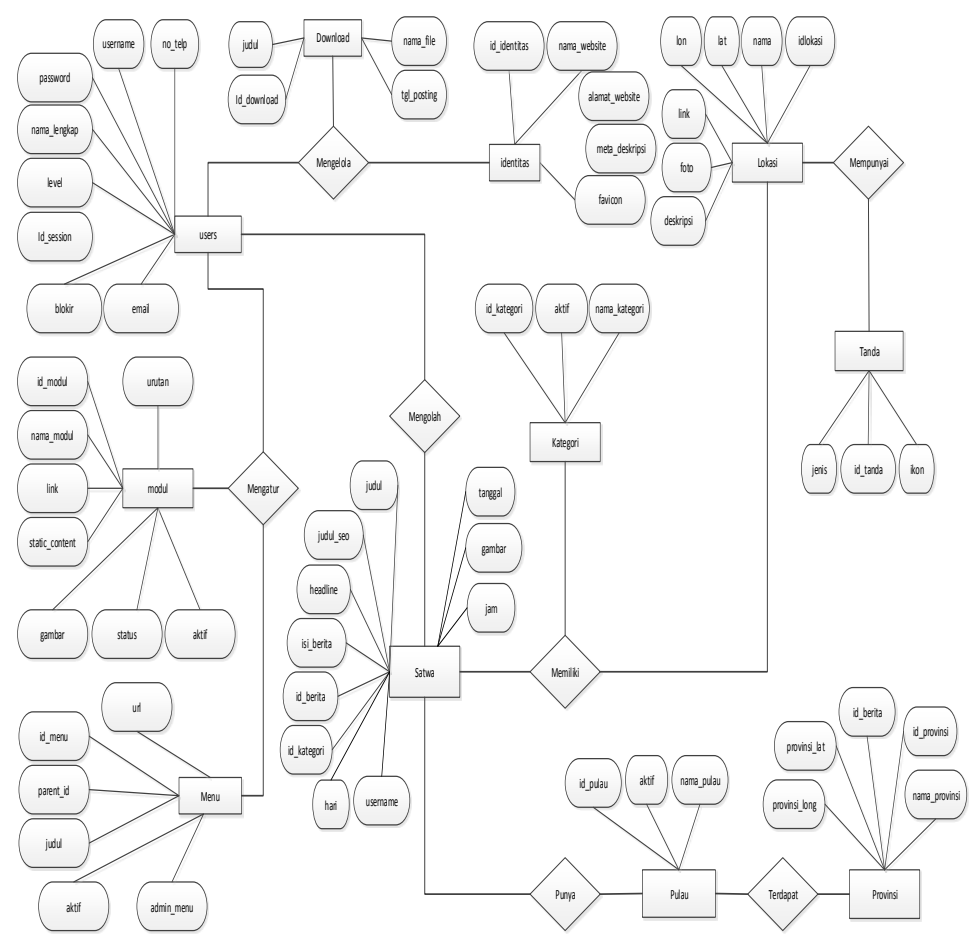

Gambar 3.4. Rancangan ERD aplikasi data satw 
Gambar 3.4 menjelaskan proses kinerja aplikasi data satwa, dimana admin dapat mengelola banyak data satwa dari semua jenis kategori satwa yang diproses pada aplikasi data satwa. Selain itu admin juga mengelola users, manajmen file dan pengaturan identitas users.

\subsection{Perancangan Antarmuka}

Setelah perancangan sistem yang menjelaskan bagaimana sistem akan berjalan, selanjutnya merancang tampilan antarmuka untuk user. Perancangan antarmuka adalah sketsa desain aplikasi yang akan dibuat. Perancangan antarmuka dibuat untuk memudahkan dalam pembuatan tampilan aplikasi.

Tampilan akan di bagi menjadi 3 bagian yaitu: Antarmuka untuk admin, Antarmuka untuk pemilik dan Antarmuka untuk pengunjung. Tampilan antarmuka admin seperti gambar berikut (tampilan Antarmuka Admin)

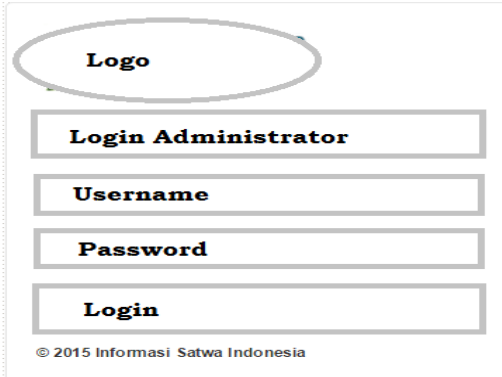

\section{Gambar 3.5. Tampilan login admin aplikasi data satwa}

Desain pada Gambar 2.5 merupakan tampilan login untuk admin / pemilik sebelum mengolah semua data yang ada pada aplikasi data satwa.

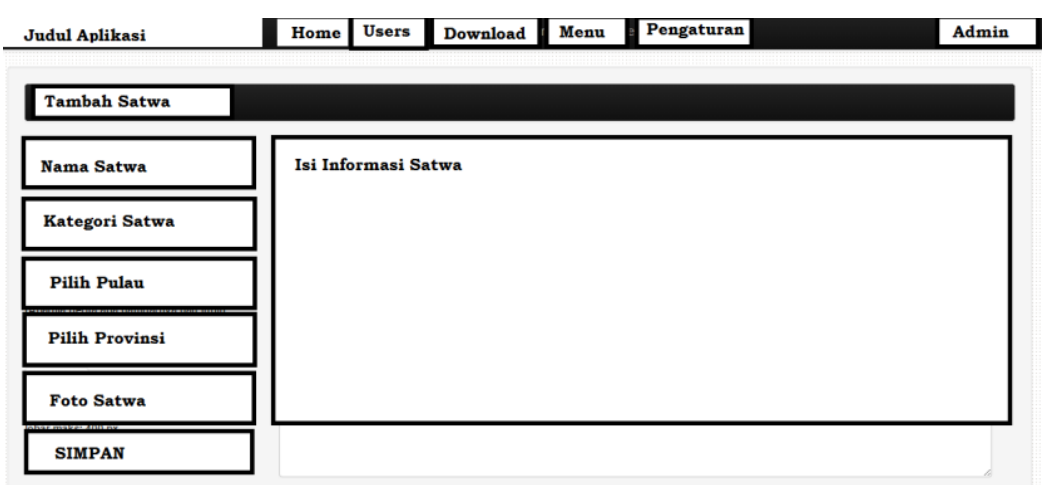

Gambar 3.6. Tampilan tambah satwa untuk admin

Desain pada Gambar 3.6 tambah data satwa dimana admin / pemilik dapat melakukan tambah informasi data satwa setelah melakukan proses sukse login. 
1.Tampilan Antarmuka Pemilik

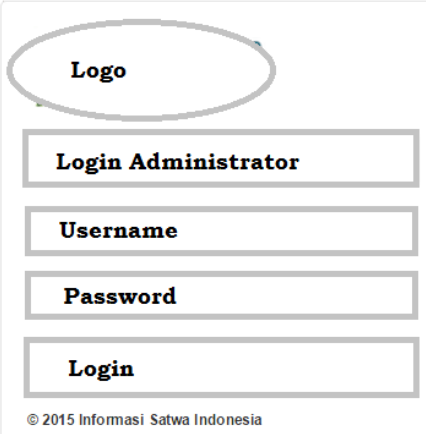

\section{Gambar 3.7 Tampilan login pemilik aplikasi data satwa}

Desain pada Gambar 2.7 merupakan tampilan login untuk pemilik, sebenarnya sama yang membedakan dalah username dan password antara admin dan pemilik, sehingga tampilan loginnya adalah sama.

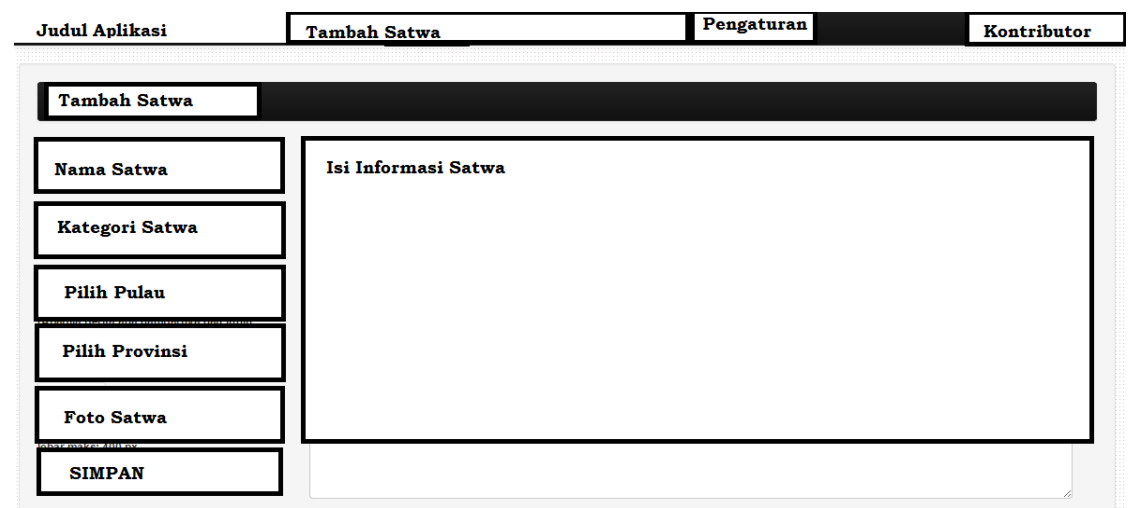

\section{Gambar 3.8. Tampilan tambah satwa untuk pemilik}

Desain pada Gambar 3.8 Tampilan tambah data satwa untuk pemilik.yang sebelumnya harus sukses login .

2. Tampilan Antarmuka Pengunjung

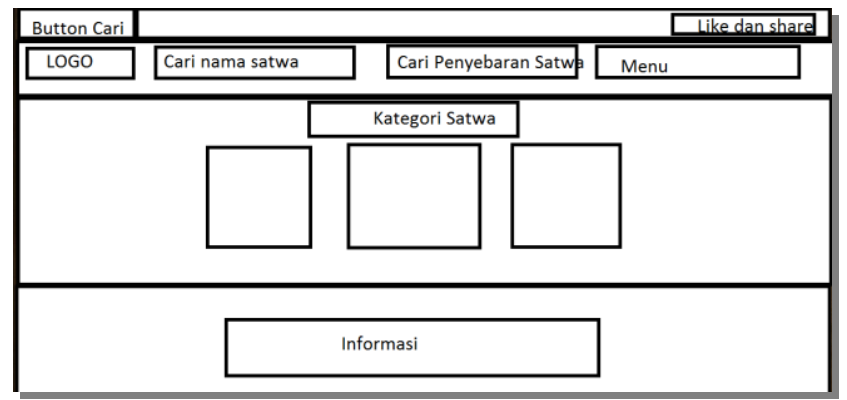

Gambar 3.9. Tampilan Home untuk pengunjung 
ISSN: 2302-2426

Desain tampilan pada Gambar 3.9 adalah desain antarmuka untuk Tampilan home/ bernada pada halaman pengunjung/msyarakat. Pada Halaman ini terdiri dari button pencarian, logo, pencarian berdasarkan nama satwa dan pencarian berdsarkan penyebaran satwa, menu utama aplikasi , pada bagian isi konten terdapat kategori satwa yang nantinya akan berupa ikon sesuai kategori satwa, dan tedapat konten informasi yaitu informasi terkait dengan satwa.

\section{HASIL DAN PEMBAHASAN}

\subsection{Uji Coba Login Admin}

Untuk bisa mengelola aplikasi data satwa harus login pada halaman login admin di aplikasi data satwa ini. Halaman login admin seperti Gambar 4.1 berikut ini.

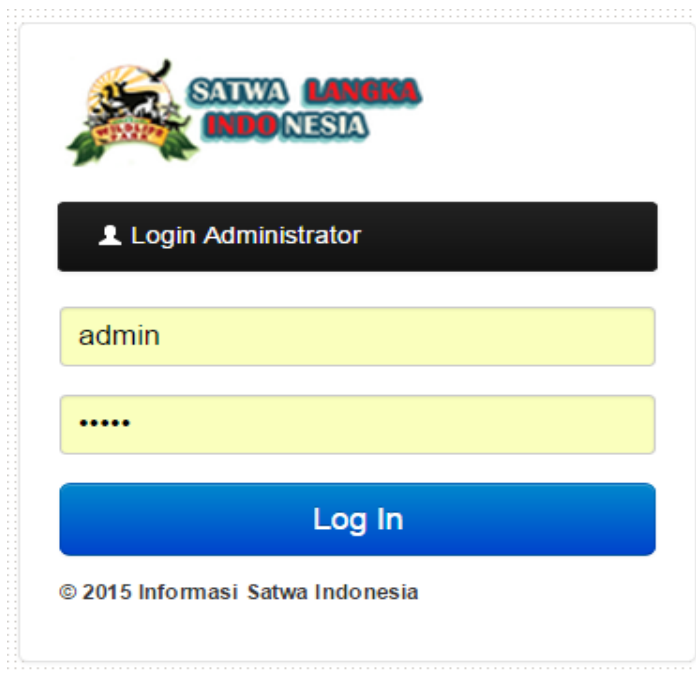

\section{Gambar 4.1. Halaman login admin}

Login pada aplikasi data satwa ini, memasukkan usename dan password, jika benar yaitu username dan password sesuai dengan yang ada di database aplikasi data satwa ini, maka aplikasi akan memproses dan menuju halaman beranda atau home. Admin bisa mengelola semua fiture di aplikasi ini, karena admin mempunyai hak akses penuh dalam aplikasi data satwa ini. Sukses login maka akan menuju halaman beranda, yaitu seperti pada Gambar 4.2. 


\section{Pengelola Info Satwa Indonesia \\ Selamat Datang \\ Salam Sukses Administrator, Anda dapat mengelola Data satwa di aplikasi ini, gunakan menu di ata}

\section{Informasi Satwa Terbaru}

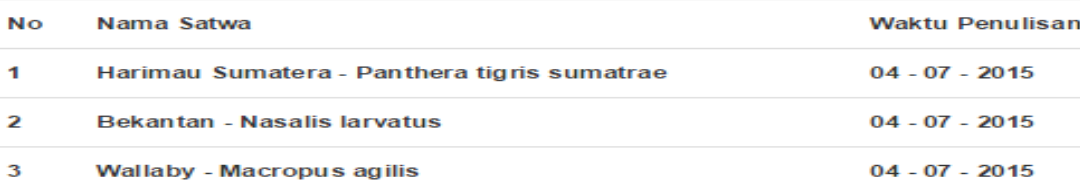

3 Wallaby - Macropus ag ilis

\section{Gambar 4.2. Tampilan halaman beranda admin}

Pada bagian menu bar terdapat beberapa menu yaitu menu home, info satwa, kategori satwa, users, dan file yang digunakan oleh admin untuk mengelelola aplikasi data satwa.

\subsubsection{Pengujian Pada Bagian Pengunjung}

Pengujian pada bagian pengunjung adalah bagian front end atau bagian yan bisa di akses oleh banyak orang untuk melihat informasi tentang satwa pengujian ini akan dijelaskan lebih detail yaitu sebagai berikut :

Untuk membuka halaman awal apliasi data satwa ini bisa menggunakan link alamat http://localhost/satwa untuk yang versi offline dan http://satwalangka.co.id/ untuk yang versi online. Halaman beranda aplikasi data satwa adalah seperti Gambar 4.3 di bawah ini.

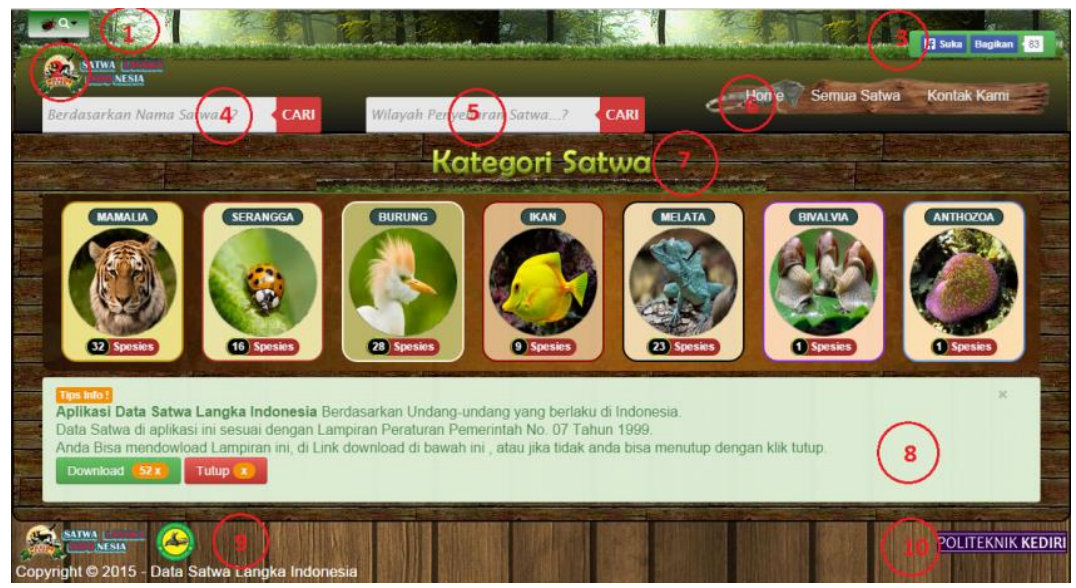

Gambar 4.3. Halaman beranda pengunjung 
Pada bagian home atau beranda pada aplikasi data satwa ini terdiri dari beberpa menu dan bagian yang mememilki funngsi masing-masing fungsi tersebut adalah sebagai berikut :

1. Button pencarian

2. Logo Aplikasi Data Satwa

3. Button Like dan share facebook Page

4. Pencarian berdarkan nama satwa

5. Pencarian berdasarkan wilayah penyebaran satwa

6. Menu Utama aplikasi data satwa.

7. Kategori Satwa dengan tampilan berupa Icon sesuai dengan kategori

8. Info tentang aplikasi dan link download File Lampiran Undang-undang tentang satwa yang di lindungi di Indonesia.

9. Copyright dan hak cipta aplikasi

10. Pengembang aplikasi.

\section{KESIMPULAN DAN SARAN}

\subsection{Kesimpulan}

Pada pembahasan bab - bab sebelumnya maka dapat diambil beberapa kesimpulan diantaranya.

1.Dari pembuatan Aplikasi Data Satwa dan berdasar teori satwa di Kebun Binatang Surabaya, Geographic Information System (GIS), Css Bootstrap, Flowchart, dan DFD pada Bab II dapat disimpulkan bahwa aplikasi data satwa yang telah dibuat dapat membantu masyarakat dalam memberikan informasi mengenai satwa langka di Indonesia yang di lindungi oleh undang-undang, terlebih software aplikasi data satwa ini telah diuji validasinya oleh pengguna.

2. Aplikasi data satwa memberikan informasi data satwa ke dalam bentuk peta dan berbasis web dengan framework css bootstrap, dan data satwa berasal dari lembaga konservasi dan kebun binatang, sehingga aplikasi data satwa ini memberikan informasi kepada masyarakat dengan data yang valid dan benar.

3.Dengan adanya Aplikasi Data Satwa dapat digunakan sebagai media informasi berbasis web melaui media internet dan dapat di akses dari berbagai lokasi yang memiliki jaringan internet. 


\subsection{Saran}

Dari pembuatan aplikasi data satwa perlu adanya pembaharuan diantaranya adalah sebagai berikut :

1.Perlu dikembangkan lagi agar aplikasi data satwa ini memiliki data yang lebih banyak dan perlu adanya kerjasama yang luas dari berbagai lembaga konservasi satwa atau kebun bianatang lain tidak hanya kebun Binatang Surabaya.

2.Perlu adanya pendataan satwa langka secara berkala sehingga aplikasi ini benar-benar bisa menjadi aplikasi yang menjadi sumber rujukan yang valid dan dapat dipertanggung jawabkan kebenaran data-data satwa yang ada pada aplikasi data satwa ini.

3. Kedepannya perlu pengembangan agar aplikasi data agar tidak hanya berbasis website, tetapi aplikasi data satwa dapat digunakan di semua platform smartphone seperti Android atau iOS.

\section{DAFTAR PUSTAKA}

[1]. Alantas, Husein., (2013). Responsive Web Design Dengan PHP Dan BOOTSTRAP. Yogyakarta : Lokomedia.

[2]. Arief, M. Rudyanto. (2011). Pemrograman Web Dinamis Menggunakan PHP dan MySQL. Yogyakarta: Andi Offset.

[3] Indrajani., (2015). Database Design (Case Study All in One). Jakarta: PT Elex Media Komputindo.

[4] Kadir, Abdul., (2013). Pemrograman Database MySQL untuk Pemula. Yogyakarta: Mediakom.

[5] Prahasta, Eddy., (2009). Mengenal System Informasi Geografis(GIS). Bandung : Informatika.

[6] Pressman, R.S., (2010). Software Engineering A Practitioner's Approach. New York : McGraw-Hill.

[7] Sukamto., \& Salahuddin., (2014). Rekayasa Perangkat Lunak Terstruktur dan Berorientasi Objek. Bandung : Informatika.

[8] Sutarman, A., (2007). Membangun Aplikasi Web dengan PHP \& MySQL. Yogyakarta : Graha Ilmu.

[9] Utomo, E.P., (2010). Cara membangun pemetaan menggunakan Google Map Api. Yogyakarta : Mediakom. 
ISSN: 2302-2426

ISSN on Line: $2580-2399$

[10] Mukhlis Ramadhan. 2009. Desain Web Dengan PHP. Yogyakarta: Jurnal SAINTIKOM, Vol. 6, No. 1, Januari 2009:1-8.

[11] Syarif Haryana. 2008. Pengembangan Perangkat Lunak Dengan Menggunakan PHP. Bandung: Jurnal Computer \& Bisnis, Vol. 2, No. 1, Juni 2008:14-21.

[12] Kementrian Lingkungan Hidup Dan Kehutanan., 2018, Lampiran Peraturan Menteri Tentang Jenis Tumbuhan dan Satwa Liar di Indonesia Yang Dilindungi[pdf],(http://ksdae.menlhk.go.id/assets/news/peraturan/P.20_Jenis_TS L_.pdf, diakses tanggal 01 September 2018 ). 